\section{Ambiguity, Cognition, Learning, Teaching, and Design}

\author{
Jan Visser \\ Learning Development Institute \\ Yusra Laila Visser \\ Learning Development Institute and \\ Florida Atlantic University
}

\section{Ambiguity. Why bother?}

Many people in the instructional design community may wonder why AECT should devote a special session during its most recent International Convention in Anaheim, CA, to the issue of ambiguity. Isn't the whole idea behind well-designed instruction that it should be ambiguity free? If at all a debate on the issue of ambiguity would be necessary, shouldn't such an exercise simply focus on possible ways to improve instructional design procedures so as to take ambiguity away to the maximum extent possible?

Not so, was the idea of a group of people brought together by the Learning Development Institute (LDI - http://www. learndev.org). The group, representing a variety of disciplines and connected in different ways to the practice and theory of cognition, learning, teaching and design, met at a special LDI workshop organized and coordinated in the framework of AECT's 2003 International Convention. The question framing their deliberations was, "What should one do in the learning environment to optimally prepare people for life in an ambiguous world?" The workshop participants subsequently served on the panel of a special discussion session open to the conference attendees at large.
What follows highlights some of the concerns that emerged from the Anaheim debate, which involved panelists, discussants, and attendees of the special session. Those concerns, then, may explain why, after all, one should bother.

\section{How it all began on the Internet}

The origins of the interest for conducting the session on ambiguity and learning is illustrative of the critical role of the Internet in connecting people from diverse geographical regions, institutional affiliations, and disciplinary areas around shared concerns. In this particular case it all started in June 2000 when an economist, Gil Suzawa of the University of Rhode Island, and a physicist with a strong instructional design interest (the first listed author of this article) started an intensive nine-month e-mail exchange, that has since continued intermittently. Suzawa initiated the dialogue by writing a simple message to his then unknown colleague:

Upon reviewing the information provided in the Learning Development Institute website, it appears that the goals and activities of the Institute closely resemble my own goals and professional interests in the domain of learning. I am attaching a file...containing a working paper entitled, "Teaching Economics 'with some Ambiguity': Implications of Transdisciplinary Inquiry," for your review.

Please get back to me if you believe that there is some "goodness of fit" between the Institute and myself.

In fact, there was. Suzawa got a same day response. LDI being a networked scholarly community, the initial contact also rapidly led to other researchers becoming involved in the online dialogue. They included David Solomon, then at Wayne State, who had just presented a paper on 
philosophical inquiry in instructional design (Solomon, 2000, February); Basarab Nicolescu of the International Center for Transdisciplinary Research and author of, among other works, Manifesto of Transdisciplinarity (Nicolescu, 2001); and the second listed author of this article who was involved in research on problem oriented learning. Later the circle broadened. Moreover, the collaboration yielded a concept paper that Suzawa contributed to the collection of LDI Working Papers (Suzawa, 2001). That paper subsequently generated the preliminary discussions around conducting a session on ambiguity at the recent annual meeting of the AECT.

\section{The Anaheim debate}

The online discussions clearly pointed towards the need to take ambiguity seriously, to see it as more than merely an inconvenience that should be avoided in an instructional context lest the mind of the learner become confused. Rather, it was recognized that ambiguity should in certain cases primarily and deliberately be acknowledged and embraced, recognizing that ambiguity is also a fact of life that anyone must learn to live with. The more complex the world, the more relevant the latter assertion becomes. The Anaheim workshop thus sought to examine ambiguity in the first place as a fact of life, rather than as something to be navigated around. Given that in real life we have to deal with ambiguity in its many guises all the time, the purpose of the session was to explore how learning and ambiguity intersect, and what the ramifications of this intersection are for the design of learning environments at all levels. The need for a discussion along these lines emerged as particularly important in the context of the instructional design community, given that instructional design theories and models have recommended varying degrees of integration of ambiguity into learning design. From the classical instructional design perspective, as mentioned, the general tendency was to recommend the elimination of ambiguity, in the interest of clarity and efficiency in instruction. As research points more strongly to the importance of contextualization and complexity in supporting the transfer of skills to outside environments, however, there has been an increase in the emphasis on providing learners with opportunities to negotiate ambiguity.

\section{The importance of process}

Preparation for the debate was as essential as the debate itself. The process was completed through several phases. First it involved inviting seven professionals to share their reflections on the session's theme. In addition to Gil Suzawa and the two authors of this paper, it expanded the discussion environment to include John Shotter of the University of New Hampshire, Muriel Visser of Florida State University, Gordon Rowland of Ithaca College and Ron Burnett of the Emily Carr Institute of Art and Design in Vancouver. Over the course of several months, written contributions from the group of now seven participating authors were added to the web site of the Learning Development Institute (http://www.learndev.org/ ambiguity.html). Together these papers represented a broad selection of disciplinary areas and perspectives, including those related to the conceptualization of learning as a dialogic and social process; the study of human behavior in situations where cognition is at odds with visceral response patterns; the science of complex systems; social criticism; problem-oriented learning; the 
teaching of economics; art and design education; and the development of mind.

Making the papers available via the Web ahead of the actual workshop allowed further debate online and thus prepared the workshop participants for an animated face-to-face open-ended discussion in Anaheim around critical issues relating to ambiguity and learning in which key themes, emerging from the various written contributions, were identified and analyzed in depth. Toward the conclusion of the workshop session, the participants met with the invited session discussants, Brent Wilson of the University of Colorado and Kyle Peck of Pennsylvania State University, to report on their preliminary conclusions and to synthesize the thematic areas.

The process concluded the following day with an open discussion session in which each of the panelists presented their individual perspectives on two or more of the thematic areas identified during the workshop. The two discussants then reflected on the collection of perspectives presented by the panel and provided their individual perceptions on the issues at stake, thus setting the scene for the ensuing debate involving the conference audience at large.

\section{Generative themes}

As noted, a list of crosscutting themes was generated that served as an organizing framework for discussion. These themes were identified (with one exception) on the basis of their perceived relevance to the topic area, as well as their relative prominence in two or more of the written contributions for the session. In concluding this short paper, we present these themes briefly below with some clarifying comments, in the hope that they will serve as a prompt to reading the more extensive elaborations and reflections that can be found at http://www.learndev.org/ ambiguity.html.

1. Mindfulness: Explicit reference to the mind was made by at least three authors in the above Web document. The idea of mind is in itself somewhat confuse because of its multiple connotations. However, transpiring from the discussion is the notion that people consciously consider their actions (and new ideas that condition those actions) against the backdrop of lived experience as engrained in their minds.

2. Kinds of language: Here the argument is that the world can be entered into at different levels. Each way of dealing with the world has its own language. Descriptions of our encounters with the world from different perspectives - e.g. scientific, religious, poetic - are often seemingly contradictory when the same words acquire different meanings depending on the kind of interaction and therefore the kind of language used. The challenge thus is to learn to live with the complementarity of seemingly contradictory ways of looking at and being present in the world.

3. Strategic/purposeful ambiguity: Instructional design recommends writing instruction that is unambiguous. However, diverse cultures are differentially tolerant of ambiguity. Removing too much ambiguity from the learning context may thus go against cultural expectations as well as lead to a level of 'dumbing-down' that will eventually reduce learners' ability to negotiate ambiguity. A strategically useful level of ambiguity in the learning environment is thus called for, once it is recognized that a 
particular instructional intervention touches upon the human being as a whole.

4. Context (as a prompt for learning): Various authors (most frequently cited among them are perhaps Tessmer and Richey, 1997) have stressed the importance of context in the design of instruction. Context has a dual function in regard of learning. It can serve as an impetus for learning and it sets the parameters for the learning experience. By nature, context, when not artificially delimited, is complex and allows learners to adopt different perspectives, thus leading to ambiguity in the learning experience. The degree of complexity - and thus the level of ambiguity - increases even further in those cases where context is social context and where one thus learns in the proximity of and in community with other human beings.

5. Vitality of learning: This idea refers particularly to what may be seen as a certain level of courage that is required of both learners and those involved in coaching other people's learning to look at each learning experience as unique and potentially new. Vitality and relevancy thus become associated concepts. Ambiguity, in the sense that the same world is also always new from any individual's perspective at a particular point in time, then becomes an essential condition for sustaining meaningfulness in the learning process, as well as for staying motivated for and committed to learning.

6. Coexistence: People can live at one time with several realities, allowing multiple, and at times mutually contradictory, knowledge domains to co-exist. The capacity to live, temporarily, in the shadowland of contradiction can be an essential condition to attain clarity and cognitive comfort at a different level at a later stage.

7. Optimization of ambiguity: Consensus transpired from the discussions that in many cases ambiguity is a healthy ingredient of the learning environment. It thus becomes relevant to identify the extent to which ambiguity should be integrated into the learning environment to ensure that the learning experience is optimized in terms of its intellectual and affective effect.

8. Wisdom: Though mentioned in writing by only one of the authors, all workshop participants converged on the recommendation that the development of wisdom should be given greater prominence in our thinking about how learning experiences and the environments in which they occur should be shaped. Wisdom involves the capacity to reflect on what we know and on what we do with what we know. It is therefore essential in allowing us to live with the ambiguity of our own existence as well as the ambiguity in the lives of our fellow human beings. It is profoundly connected with the notion that knowledge is transitory, in addition to being contextualized and grounded in the practice of our lives.

9. The role of the instructional designer: The critical question here is whether instructional designers should define their role targeting the development of the whole-person, or whether their role should be seen as 
limited to ensuring skills development in restricted areas and for specific purposes only. The answer to the question must probably be ambiguous in its own right, depending on the context in which it is asked. Agreement emerged, though, regarding the importance of continually raising the question and searching for the right balance in finding multiple answers.

10. Creativity: This is a 'last but not least' issue transpiring from both the written and oral contributions of virtually all contributors to the Anaheim debate. They recognize that the essence of creativity is the emergence of something new and that ambiguity is the necessary space within which creativity operates. The idea contradicts the Cartesian picture of the world that western civilizations have grown to live with and become accustomed to for centuries. "But clearly and crucially" - as one of the authors, deliberately not referenced here to encourage further exploration of the Web document, wrote - "what is missing from such a picture, is life, the activities of living, embodied beings, and the fact that for us here on earth, life does not come from a mysterious god on high, but only from other life, in an unbroken chain of creativity that occurs whenever two or more living forms meet, and actively 'rub up against' each other, so to speak."

\section{Notes}

1) The authors of this article list their names alphabetically as they recognize that their collaborative effort has contributed to the final product in equal measure.
2) This is the first of two articles by authors associated with the Learning Development Institute (LDI), reporting on two special sessions conducted by LDI at the recent Anaheim Convention. A second article, on "A cornucopia of problems," authored by Jan Visser, Muriel Visser and Ron Burnett will appear in the next issue of TechTrends.

\section{References}

Nicolescu, B. (2001). Manifesto of Transdisciplinarity. New York: SUNY Press.

Solomon, D. L. (2000, February). Philosophical inquiry in instructional technology: The forgotten pathway to learning (Report No. IR-019974). Paper presented at the Annual Convention of the Association for Educational Communications and Technology, Long Beach, CA. [Also available online at http://www.learndev.org/dl/ SolomonPhilosophy.PDF].

Suzawa, G. S. (2001). The role of ambiguity in learning. LDI Working Papers, 3 [Online]. Available http://www.learndev.org/dl/SuzawaAmbiguityDiscPap.PDF [2003, December 6].

Tessmer, M. and R. C. Richey. (1997). The role of context in learning and instructional design. Educational Technology Research \& Design, 45(2), 85-115. 